\title{
Interest Rate Prediction with Taylor Rule
}

\author{
T. Bouchabchoub, A. Bendahmane, A. Haouriqui, and N. Attou
}

\begin{abstract}
This paper presents simulation results of Forex predicting model equations in order to approximately give a prevision of interest rates. First, Hall-Taylor (HT) equations have been used with Taylor rule (TR) to adapt them to European and American Forex Markets. Indeed, the initial Taylor rule equation is conceived for all Forex transactions in every State: it includes only one equation and six parameters. In this work, the model has been predicted with Hall-Taylor equations, initially including twelve equations which have been reduced to only three. Analysis has been developed on the following base macroeconomic variables: real change rate, investment wages, anticipated inflation, realized inflation, real production, interest rates, gap production and potential production. This model has been used to specifically study the impact of an inflation shock on macroeconomic director interest rates.
\end{abstract}

Index Terms-Interest rate, forex, Taylor rule, production, European Central Bank (ECB), Federal Reserve System (FED).

\section{INTRODUCTION}

Various macroeconomic models have been developed in order to analyze the evolution of Central Bank interest rate and its impact on the Forecast of FOREX market. Taylor rule theory [1] stipulates that Central Bank should change nominal interest rates according to changes in inflation, output or other economic parameters and conditions fixed on Taylor rule equation. Indeed, these financial changes are caused by the gross domestic product (GDP), the random fluctuations (stochastic shocks) along with the divergence of actual inflation rates from target inflation. Taylor rule leads to a result showing the direct impact of inflation increase on Central Bank interest rate. Consequently, if inflation rate increases, the real interest rate should also be increased. Many theoretical modifications have been proposed, leading in that way, to the new Hall-Taylor (HT) model [1]. Here, Central Banks use dynamic stochastic general macroeconomic models and HT model to define their directing rates, particularly in Europe, with the European Central Bank (ECB). These models are based on general equilibrium theory describing equilibrium between supply and demand on all markets. HT is a model with 12 equations, containing several parameters and macroeconomic factors. The Sphere of good and services [1] is one of the first groups of equations in HT model. It is used in order to globally analyze productivity, consumption, investments and their impact on other parameters and on the economy. Unlike other models, HT

Manuscript received June 17, 2014; revised October 18, 2014.

The authors are with Undergraduate students ECE Paris School of Engineering, France (e-mail: bouchabc@ece.fr). model includes deeper structural parameters describing inflation preferences, productivity and other component constraints [2]. The model also includes a system of equations describing three classes of economic fields: net export, state deficit and unemployment rate. Indeed, it includes all together three elements: the Central Bank monetary policy impact on net export, the productivity impact on unemployment and the deficit combined to production effect on general deficit. HT model essentially takes into consideration seven macroeconomic variables by restraining them to inflation and real rate exchange fields: real change rate, anticipated inflation, realized inflation, real production, interest rates, gap production and potential production in considered Euro zone.

\section{MODEL DEFINITION}

Financial crises have generated a huge cost of banking system failure on overall economy, which led governments and Central Banks to worry more about financial stability. One of the best solutions in this case turned out to be the rate analysis in order to help find an exact prediction.

The European Central Bank is responsible for monetary policy of all the countries that have adopted the euro. The national central banks have become mere agents of the European Central Bank, as they are in charge of the implementation of the single monetary policy that is agreed within the European Central Bank, which sets interest rates for the entire area. Moreover, since the early ninety years, economic researches on the topic of monetary policy rules have increased significantly. In particular, the work of Taylor in 1993 had a considerable impact. By estimating a monetary policy rule in the United States, he showed that the monetary authorities followed a simple rule based on an inflation target conjugation and a production target. The aim of our work is to consider the study of the rule abided by the European Central Bank following the methodology of Taylor.

In the present study, the Taylor rule is used, knowing that it mechanically connects the level of interest rates, controlled by the central bank, inflation and the output gap, all in a very short term. It was presented by Taylor in 1993 and was estimated for the United States.

The Taylor rule takes generally the main following form:

$$
r=r_{\text {neuter }}+p_{\text {anticipated }}+\alpha_{1} y+\alpha_{2}\left(p_{\text {anticipated }}-p_{\text {goal }}\right)
$$

where: $r=$ nominal interest rate Taylor (calculated), $r_{\text {neuter }}=$ neutre 1 real long-term rates (constant equal to the trend rate of growth of the economy), panticipated=expected inflation (approximated by the delayed inflation) 2 , $p_{\text {goal }}=$ inflation target of the monetary authorities, $y=$ difference between actual GDP and trend GDP, as: $y=1000\left(Y-Y^{*}\right) / Y, Y$ : actual GDP (real) \& $Y^{*}$ : trend GDP. 
According to the Taylor rule, the short-term interest rate should increase when expected inflation exceeds the inflation target of the central bank or when the product Gross domestic workforce is above its long-term trend.

For the U.S, Taylor proposed this equation:

$$
r=2+p+0,5 y+0,5(p-2)
$$

where $r=$ federal funds rate; $p=$ inflation rate of the last 4 quarters; $y=$ output gap between actual GDP $(Y)$ and trend GDP $(Y *)$, with $Y *=2.2 \%$ per year between 1984.1 and 1992.3 and $\alpha_{1} \& \alpha_{2}=0,5$,

The values of the coefficients 1 and 2 are both 0.5 , these values are specific to the case of the United States, and are justified by a concern for pragmatic realism of the rule. However, Taylor acknowledges that these factors may be different in other countries.

Indeed, the Taylor rule gives a relationship between target Central Bank short-term nominal interest rate and real interest rate. This relation contains six macroeconomic parameters (the target short- term nominal of Central Bank interest rate, the inflation rate, the Central Bank inflation target, the real interest rate and the respective levels of GDP and potential GDP). Equations of HT model have been used to find the inflation gap, and the relationship between exchange rates and interest rates; in order to understand the rule followed by the European Central Bank, we have to define the output gap between the potentially achievable gross domestic product in Europe during this period and the domestic product found. For this purpose, there are various solutions including three different methods: the first one based on a linear fit, the second on the quadratic fit and the last one on smoothing the output observed with the Hodrick-Prescott, with keeping in mind that these are alleged methods, and that the latter method is particularly sensitive to extreme dates of the sample.

In this work, the production gap is determined by using Kalman filter [3] which gives more satisfactory results than other methods. The inflation gap is an important factor involved in Taylor rule: it represents the difference between actual and expected inflation.

Inflation evolution between 2001 and 2009 is reported on Fig. 1.

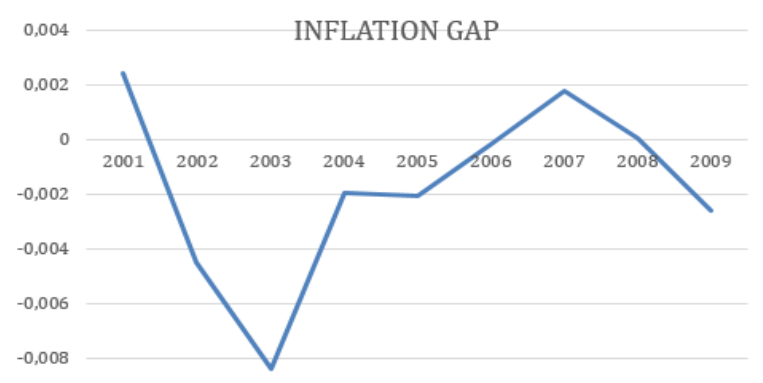

Fig. 1. Evolution of inflation gap vs time between 2001 and 2009.

The equation used for simulation is

$$
\pi_{\exp }=\alpha \pi_{-1}+\beta \pi_{-2}
$$

where $\pi_{\exp }$ is expected inflation, $\pi_{-k}$ the inflation during quarter $t-k$ and $\alpha=.4, \beta=.2$. The other needed parameter in addition to inflation is the production gap, often confused with GDP, and which occurs in the smoothing part to predict Center-Bank director rate. It is also found in HT equation involving both inflation and output gap:

$$
\pi=\pi_{\exp }+f\left[Y_{N-1}-Y_{N}\right] / Y_{N}
$$

where $Y_{N-1}$ is the production during previous quarter, $Y_{N}$ the production during actual quarter and $f=.8$. As mentioned previously, smoothing with Kalman filter [3] is an important tool in forecasting financial parameters. Its use in this case is only valid for output gap prediction and, from Taylor rule, the interest rate referring to EUR/USD pivot [4]-[7] can be found. GPD evolution is reported on Fig. 2.

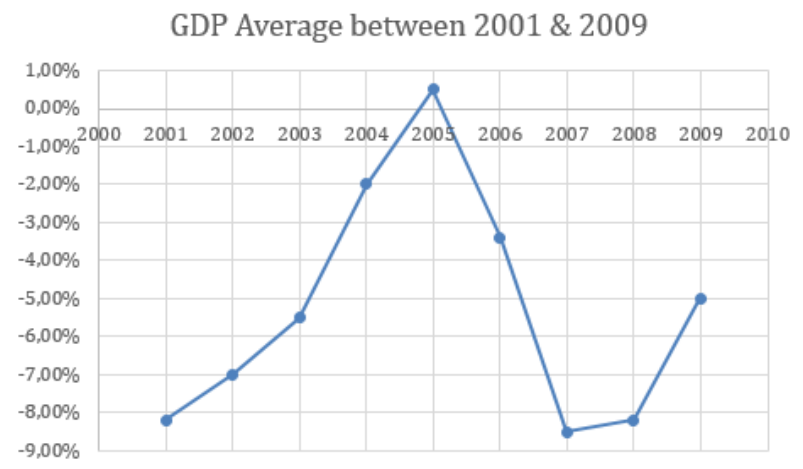

Fig. 2. Production differential evolution vs time between 2001 \& 2009.

Taylor rule writes:

$$
i_{t}=\pi_{t}+r_{t}+\alpha_{t}\left(\pi_{t}-\pi_{t}^{*}\right)+\alpha_{y}\left(y_{t}-y^{*}\right)
$$

With inflation gap, $\left(\tilde{\pi}_{t}-\pi_{t}^{*}\right)$ output gap $\left(y_{t}-y^{*}\right)$, interest rate $r_{t}$, inflation $\pi_{t}$, policy rate $i_{t}$ and parameters $\alpha_{t}=$ $0.3, \alpha_{y}=0.6$.

As a result, the EUR/USD pivot [5]-[7] can automatically be found through ECB rate. As there are two unknown and a single equation (3), it is not possible yet to find researched predictive value rate. Missing information should in principle be reconstituted by including a new equation, but the difficulty stems from the strong relationship between macro variables in any macroeconomic model, which forbids such a "simple", logical approach, and requires a full set of equations in order to be closed. Here, the following two "empirical" equations will be considered:

$$
\begin{gathered}
y_{t}=\phi_{0}+\phi_{1} y_{t-1}+\phi_{2} y_{t-2}+\lambda\left(i_{t-1}-\pi_{t-1}^{-}\right)+\varepsilon_{y, t} \\
\pi_{t}=\sum_{i=1}^{4} \alpha_{i} \pi_{t-i}+\beta y_{t-1}+\varepsilon_{\pi, t}
\end{gathered}
$$

(4) gives GPD predicted value which is useful to find production gap, and (5) produces a predicted value of inflation. Second equation is similar to a Phillips curve linking inflation to production gap dynamics of output gap. Potential GDP follows a random walk with deterministic drift. The model represented by $(4,5)$ provides a very simplified view of economy dynamics, but still allows to give a consistent production gap and a theoretical content estimate that is more substantial than a usual simple decomposition of purely 
statistical trend-cycle. Rewriting $(4,5)$ in state space representation form one gets

$$
\begin{aligned}
& \left(\begin{array}{l}
\Delta Y_{t} \\
\pi_{t}
\end{array}\right)=\left(\begin{array}{cc}
1 & -1 \\
0 & \beta
\end{array}\right)\left(\begin{array}{l}
y_{t} \\
y_{t-1}
\end{array}\right)+\left(\begin{array}{l}
\mu \\
\sum \\
j=1 . .4
\end{array} \alpha_{j} \pi_{t-j}\right)+\left(\begin{array}{l}
\varepsilon_{Y, t} \\
\varepsilon_{\pi, t}
\end{array}\right) \\
& \left(\begin{array}{l}
y_{t} \\
y_{t-1}
\end{array}\right)=\left(\begin{array}{cc}
\phi_{1} & \phi_{2} \\
1 & 0
\end{array}\right)\left(\begin{array}{l}
y_{t-1} \\
y_{t-2}
\end{array}\right)+\left(\begin{array}{cc}
\lambda & \phi_{0} \\
0 & 0
\end{array}\right)\left(\begin{array}{l}
\mu \\
\sum_{j=1 . .4} \alpha_{j} \pi_{t-j}
\end{array}\right)+\left(\begin{array}{l}
\varepsilon_{y, t} \\
0
\end{array}\right)
\end{aligned}
$$

This model includes two measurements and two transition equations. The log-likelihood is calculated by Kalman filter, and its maximization provides optimal estimators of model production gap using information over the entire period.
On the other hand, advantage is taken of INSEE study [8] which allows finding an equation relating ECB policy rate with FED variation rate. Chronological review of FED and ECB rate decisions suggests that movements of US interest rates precede ECB decisions (see Fig. 3).

There is indeed a positive correlation between ECB exchange rate and last known variation of FED rate. However, this observation does not come from a copycat behavior of $\mathrm{ECB}$, taking into account the conditions in Euro area, but much more from the fact that FED rate director is not significant. The apparent discrepancy between FED and ECB [8]-[10] decisions is captured by macroeconomic variables which react to ECB decisions, and can therefore be attributed to a mismatch between macroeconomic cycles on both sides of the Atlantic.

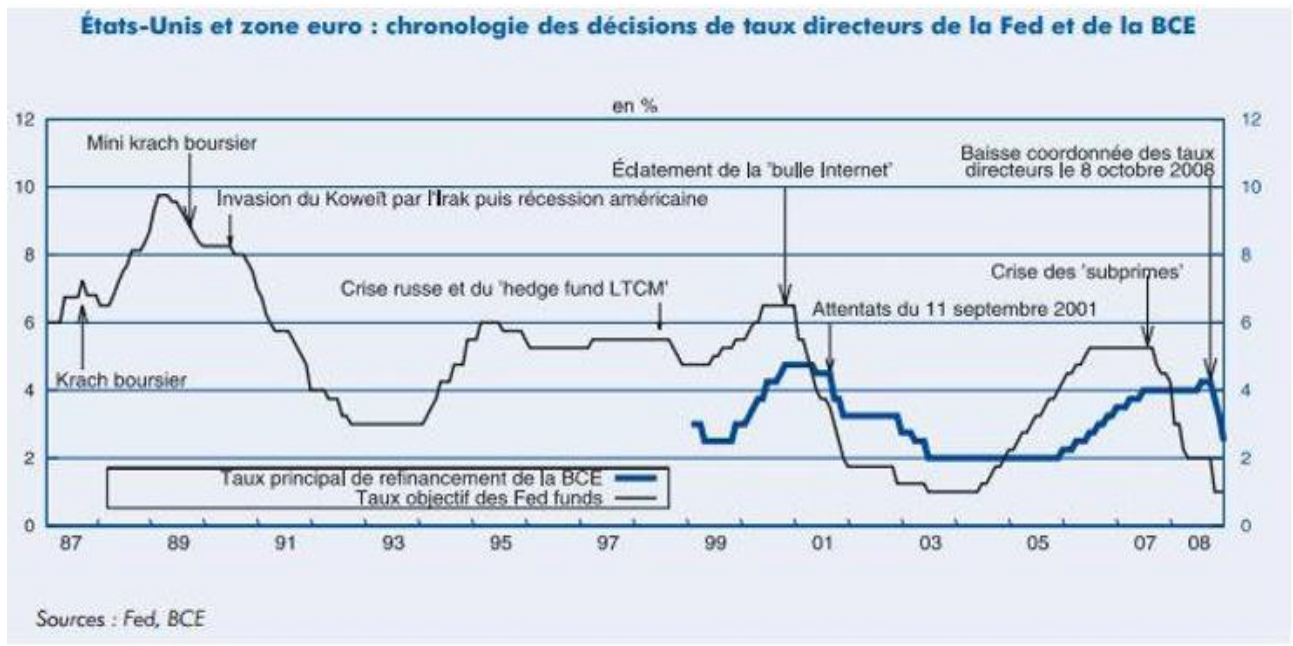

Fig. 3. ECB and FED rates vs time.

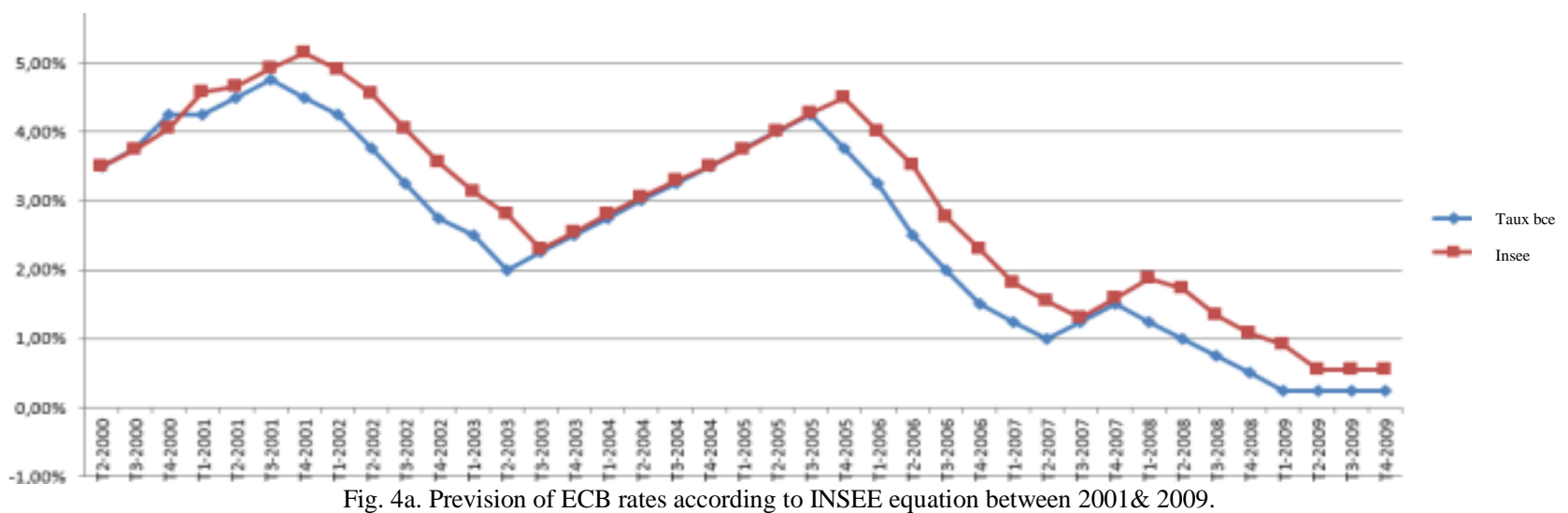

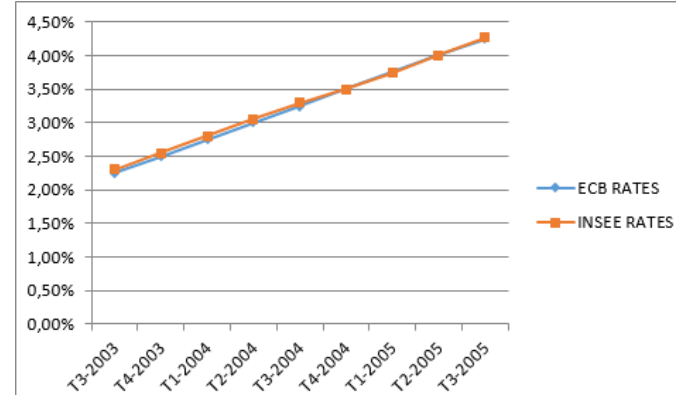

Fig. 4b. Prevision of ECB rates according to INSEE equation between $2003 \& 2005$.

The (phenomenological) equation given by INSEE writes:

$$
\begin{aligned}
& i_{t}=-5.48+.83 i_{t}-1+.21 E-1(\pi+12)+ \\
& 0.006\left(q-3-q-3^{*}\right)+.07 T U C-2+.04 \Delta F e d t-1
\end{aligned}
$$

With $E-1(\pi+12)$ the last consensus forecast of European inflation over preceding year, $q-3-q-3^{*}$ the output gap during last quarter, TUC -2 the production capacity usage rate, and $\Delta F e d t-1$ the variation of federal fund rate during previous quarter. As seen on Fig. 4a, prevision with INSEE equation almost coincides with ECB real rate on a remarkably long time interval, even including the great 2007 financial crisis [8], [10]. 
As seen from Fig. 4a, prevision with INSEE equation [8]-[10] is roughly the same as ECB real rates (in stable periods), especially during 2003-2005 (Fig. 4b) which corresponded to a period of economic stability in general. At other periods the two curves show a significant difference which may be explained by two very important events: the attack of 11 September 2001 and the subprime crisis that began in 2006. By combining (3) and (6) a final equation gives the director rate, and therefore the interest rate.

\section{CONCLUSION}

To sum up, the application of the Taylor rule on monetary policy rules could be adapted to the case of monetary policy of the European Central Bank as well, just take this policy as strict inflation target first but other data theoretical incentive to think she might consider diversifying its target by focusing on other elements such as GDP.

There are many other models [11]-[16] that give some interesting results. Present study is essentially based on Taylor model used in the United States. With the help of Kalman filter, the equation set by INSEE (National Institute for Statistics and Economic Studies), we can provide an ECB rate and awe could find an approximate value of interest rate. Prediction can be short-termed and even long-termed though predictive power fades away for long periods.

As with other estimated methods, the European Central Bank does follow a simple rule "similar" to the Taylor rule, which is based on one or two major economic aggregates as targets. However, depending on the method used to estimate the output gap between gross domestic product and made potentially feasible gross domestic product, we do not get the same results. In a first method, we get the European Central Bank's target inflation, but it is only with the two other methods, that we get a contrary result to the indication of the European Central Bank, the Taylor rule, that is to say, a rule combining an inflation target and an emerging target production.

In the same way, GDP inflation and interest rates can be predicted, but the global economy is also dependent on other factors, be it social, natural or exceptional like 9/11 bombings or subprime crisis, which can affect rates evolution.

\section{ACKNOWLEDGMENTS}

The authors are very much indebted to ECE for having provided the environment where the project was developed, to $\operatorname{Pr} \mathrm{V}$. Lebreton for guidance during the development of the work and to Pr. M. Cotsaftis for help in preparing the manuscript.

\section{REFERENCES}

[1] D. H. Papell, Hall and Taylor's Macroeconomics, 4th ed. New York, 1993

[2] A. Nikolsko-Rzhevskyy and D. H. Papell, "Taylor rules and the great inflation," J. Macroeconomics, vol. 34, no. 4, pp. 903-918, 2012 .

[3] O. Chagny and M. Lemoine, "Ecart de production dans la zone Euro- une estimation par le Filtre de hodrick-prescott multivarié," Revue de l'OFCE, no. 86, March 2003.
[4] V. Borgy, J. Idier, and G. Le Fol, "Liquidity problems in the FX liquid market," Working Paper no. 279, Banque de France, March 2010.

[5] C. J. Neely, "Technical analysis on the foreign exchange market: A Layman's guide," Federal Reserve Bank of St Louis Rev., vol. 79, no. 5, pp. 23-38, 1997.

[6] M. Darmoul and M. Kouki, "Announcement effect and intraday volatility patterns of euro-dollar exchange rate: monetary policy news arrivals and short-run dynamic response," in Proc. XIX SFSIC Congress, Toulon Univ., France, 4-6 June, 2014.

[7] J.-S. Mésonnier and J.-P Renne, "Règle de Taylor et Politique Monétaire dans la Zone Euro," Report NER\#117, Banque de France, Oct. 2004

[8] J.-C. Bricongne and J.-M. Fournier, "Note de conjoncture récessions," Dossier no. 2-Comment Anticiper les Décisions de la BCE et de la FED, INSEE, Dec. 2008

[9] K. Ullrich, "A comparison between the fed and the ECB taylor rules," Centre for European Economic Research (ZEW), Discussion Paper no. 3-19, Feb. 2003

[10] J. Klosear and A. H. Belke, "Do the ECB and the Fed react to financial market uncertainty," Ruhr Economic Paper no. 166, DIW Berlin Discussion Paper no. 972, Feb. 1, 2010.

[11] J. Benchimol and A. Fourcans, "Money is a DSGE framework with an application to the EURO zone," J. Macroeconomics, vol. 34, no. 1, pp. 95-111, 2012.

[12] E. Keogh and M. Pazzani, "Scaling up dynamic time warping for data mining applications," in Proc. 6th ACM SIGKDD Intern. Conf. on Knowledge Discovery and Data Mining, 2000, pp. 285-289.

[13] T. Kohonen, Self-Organizing Maps, Springer, Berlin, 1995.

[14] A. Bargiela and W. Pedrycz, "Recursive information granulation: aggregation and interpretation issues," IEEE Trans. on Systems, Man, and Cybernetics-Part B: Cybernetics, vol. 33, no. 1, pp. 96-112, 2003.

[15] K. Kalpakis, D. Gada, and V. Puttagunta, "Distance measures for effective clustering of ARMA time- series," in Proc. IEEE Intern. Conf. on Data Mining, pp. 273-280, 2001

[16] Y. Xiong and D. Y. Yeung, "Time series clustering with ARMA mixtures," Pattern Recognition, vol. 37, no. 8, pp. 1675-1689, 2004.

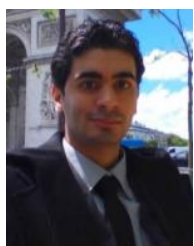

T. Bouchabchoub was born in Kenitra on July 15, 1991 in Morocco. He had a bachelor degree in mathematics and did three years of preparatory classes for engineering schools optioning mathematics. He is currently studying financial engineering at ECE Paris Engineering School, Paris. He worked as an assistant on his internship at SOTRAMEG, Morocco. His research focuses on the new alternative of finance, Islamic finance and the extend of its innovating products.

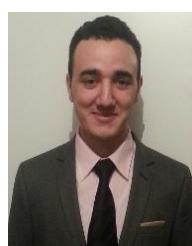

A. Haouriqui was born in Rabat on November 22, 1991. $\mathrm{He}$ is a student on the $4^{\text {th }}$ year in financial engineering at ECE Paris Engineering School, Paris, France. He got a high school diploma in mathematics at Abi dar El Ghifari, Morocco and a high school diploma in mathematics at Abi dar El Ghifari High School, Rabat, Morocco. His research focuses on the fluctuations of the interest rates, inflation and their impacts on the economy of the world.

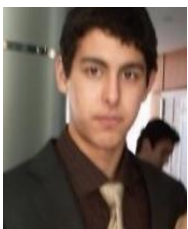

M. N. Attou is skillful in mathematics and accounting with majoring in finance. He has the international scientific baccalaureate. His role in this project is to research and study the mathematical aspects of the models and equations that were chosen to find the parameters and solutions of the problem.

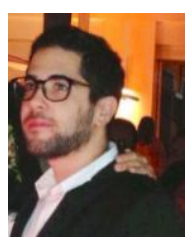

A. Bendahmane was born in Rabat on October 21, 1992. He earned a French baccalaureate with honors in Lycee Descartes, Rabat, Morocco in 2010, and continued to pursue a financial engineering degree at ECE in Paris. Currently he is doing a master thesis entitled "Ingenieur Master 1 Finance". He worked as a banking services intern in the Financial Institution Finsbury Trust \& Corporate in Gibraltar and interned in one of Morocco's leading banks, Attijari Wafa Bank, as a business project unit intern. Currently he is a control department intern at Dekra in Paris. 